\title{
CORRESPONDENCE
}

\section{NIH revamp: US health care at fault}

Contrary to Michael Crow's implications (Nature 471, 569$571 ; 2011)$, the annual budget of the US National Institutes of Health (NIH) of US $\$ 31$ billion is only a small percentage (barely $1 \%)$ of yearly US health spending - now $\$ 2.5$ trillion.

US health care is costly because it is the only wealthy industrialized country without public health insurance. Its citizens give vast sums to insurance companies whose primary function is to bleed money from the system while maximizing profit.

Everyone should benefit when an NIH-funded discovery is made that extends human life. But a shamefully large fraction of the US population does not because they have inadequate health insurance, if any. More politically enlightened nations stand to gain more by providing the best possible health care.

Thomas E. DeCoursey Rush University Medical Center, Chicago, Illinois, USA. tdecours@rush.edu

\section{NIH revamp: real issue is resources}

A failure to translate the United

States' global leadership in

biomedical science into a comparable position in health care (Nature 471, 569-571; 2011) does not justify dismantling the very source of that leadership the National Institutes of Health (NIH). The real issue is that more science, data and resources are needed by other units of the US Department of Health and Human Services (HHS) responsible for engineering the application of discoveries.

Opportunities for scientific reorganization in the NIH include improving cost-effectiveness and instrumentation of assets and weaknesses. But it is crucial to separate the engine of discovery from the engine of application. Discovery is stochastic and opportunistic; application is the stuff of engineers. That is why attempts to over-engineer discovery fail and why science should not drive its application.

There should be separate units to promote discovery, assess outcomes and engineer the healthcare system. At present, these approximate to the NIH, the Agency for Healthcare Research and Quality, and HHS units such as the Food and Drug Administration.

Russ Altman Stanford University, Stanford, California, USA. russ.altman@stanford.edu

\section{NIH revamp: avoid a redundant revolution}

A restructuring of the US

National Institutes of Health

(NIH) to include new institutes

for "health transformation"

and for research into "health

outcomes", as Michael Crow

advocates (Nature 471, 569-571;

2011), is unnecessary. These

would duplicate the function of agencies that, like the NIH, are already overseen by the Department of Health and Human Services.

The Agency for Healthcare Research and Quality focuses on outcomes research. The National Coordinator on Health Information Technology and the Centers for Medicare \& Medicaid Services (CMS) focus on transformation. In particular, the CMS will administer US $\$ 10$ billion from the 2010 Affordable Care Act for research related to sustainable cost models for health care (http://innovations.cms.gov). John Robinson South Dakota State University, Brookings, South Dakota, USA. john.robinson@sdstate.edu

\section{UNESCO helps manage tsunamis}

In disasters on the scale of Japan's 11 March tsunami, every second counts in making accurate information available to those who need it most. To this end, the United Nations Educational, Scientific and Cultural Organization (UNESCO) helps professionals and populations to anticipate the risks, assess possible flooding and coordinate monitoring.

Some lessons have been learned from the ravages of the 2004 tsunami in the Indian Ocean. In addition to the Pacific early-warning systems, UNESCO's Intergovernmental Oceanographic Commission is coordinating the set-up of regional tsunami-warning centres in the Indian Ocean, the Caribbean, the north-east Atlantic and the Mediterranean, as well as full-scale simulation exercises.

International scientific cooperation can help in countering such disasters, whose scope extends beyond frontiers and state capacity. But this cannot replace the authority and initiative of national leaders. We also need to do much more to strengthen the capabilities of local communities.

Managing the unexpected depends on education and culture. For example, Japanese children are taught how to respond to earthquakes and tsunamis at school; and because the people of Simeulue Island in Indonesia were aware of tsunami warning signs, only seven died in the 2004 event. With UNESCO's support, Indonesia and Thailand are accelerating their risk-reduction education. Last year, students and teachers were trained in schools across six coastal cities in Colombia, Ecuador, Peru and Chile.

Urbanization and uncontrolled development threaten the coral reef and mangrove ecosystems that mitigate the force of tsunamis. As some $10 \%$ of the global population live in low-lying coastal zones, protecting these natural barriers is also a shared responsibility.

Irina Bokova Director-general of UNESCO, Paris, France.

dg@unesco.org

\section{It is rational to doubt Fukushima reports}

Officials have no right to dismiss as "irrational" the public's mistrust of official pronouncements about the 11 March earthquake and tsunami damage to Japan's nuclear reactors in Fukushima.

The public in Japan and elsewhere has figured out two things about Fukushima. First, what might happen next is a potentially bigger problem than what has happened so far; and second, governments, experts and authorities have been consistently behind the curve in talking openly about what might happen next.

People are suspicious of official assurances that the current situation will get no worse, maybe rightly. They don't trust the authorities to tell them the ways in which it could get worse and how likely it is to do so. Many don't even trust the authorities to tell them promptly if it does.

As a result, a variety of precautions that might be considered excessive or premature if the public felt they could trust the authorities avoiding Japanese foods, for example, or seeking out a supply of potassium iodide - suddenly become sensible and should not be branded as illogical, hysterical or radiophobic.

Peter M. Sandman, Jody Lanard Risk Communication Consultants, Princeton, New Jersey, USA. peter@psandman.com 